\title{
Pelatihan Character Building untuk Meningkatkan Psychological Well-Being pada Anak Panti Asuhan Puteri Aisyiyah Medan
}

\section{Training of Character Building To Improve Psychological Well-Being In Children of The Puteri Aisyiyah Medan Orphanage}

\author{
Rianda Elvinawanty(1), Emi ${ }^{\left(2^{*}\right)}$, Kelsi Amanda(3), Erina Septianti(4) \& Adela Natasya ${ }^{(5)}$ \\ Fakultas Psikologi, Universitas Prima Indonesia, Indonesia
}

Disubmit: 11 Oktober 2021; Diproses: 12 Oktober 2021; Diaccept: 30 Oktober 2021; Dipublish: 02 Desember 2021

*Corresponding author: E-mail: Emiiangg5600@gmail.com

\begin{abstract}
Abstrak
Tujuan dilakukannya studi ini ialah untuk memahami pengaruh pelatihan character building untuk meningkatkan psychological well-being pada anak Panti Asuhan Puteri Aisyiyah Medan. Hipotesis pada studi ini ialah bahwa pelatihan character building efektif untuk meningkatkan psychological well-being pada anak Panti Asuhan Puteri Aisyiyah Medan. Riset ini adalah riset percobaan pada desain one group pretest-posttest design. Data yang didapatkan diuji normalitasnya memakai uji Shapiro-Wilk. Teknik analisis yang dipakai pada studi ini ialah kuantitatif serta kualitatif. Analisis kuantitatif menggunakan pengukuran non-parametrik yaitu teknik analisis statistik Wilcoxon dengan program bantuan Statistical Product and Service Solution (SPSS) versi 23. Sedangkan analisa kualitatif bersumber pada data hasil studi dan interviu. Hasil uji statistik yang selesai dibuat memakai uji Wilcoxon terdapat nilai $\mathrm{p}$ value sejumlah $0.000(\mathrm{p}<0.05)$ sehingga hipotesa diterima. Oleh karena itu, menurut hasil analisis tersebut bisa ditarik kesimpulan bahwasannya pelatihan character building berpengaruh untuk meningkatkan psychological well-being pada anak Panti Asuhan Puteri Aisyiyah Medan.
\end{abstract}

Kata Kunci: Character Building; Psychological Well-Being

\begin{abstract}
The purpose of this research is to find out the influence of character building training to improve psychological well-being in children of Puteri Aisyiyah Medan Orphanage. The hypothesis in this study is that character building training is effective to improve psychological well-being in children of Puteri Aisyiyah Medan Orphanage. This research is an experimental study with the design of one group pretest-posttest design. The data obtained was tested for normality using the Shapiro-Wilk test. The analysis techniques used in this study are quantitative and qualitative. Quantitative analysis using nonparametric measurements is Wilcoxon's statistical analysis technique with the assistance program Statistical Product and Service Solution (SPSS) version 23. While qualitative analysis is sourced from observation and interviu data. The results of statistical tests that have been conducted using Wilcoxon test obtained a value of $p$ value of $0.000(p<0.05)$ thus Ha received. Therefore, based on the results of the analysis can be concluded that character building training has an effect to improve psychological well-being in children of Puteri Aisyiyah Medan Orphanage.
\end{abstract}

Keywords: Character Building; Psychological Well-Being

DOI: https://doi.org/10.51849/j-p3k.v2i3.118

Rekomendasi mensitasi :

Elvinawanty, R., Emi, Amanda, K., Septianti, E., Natasya, \& A. (2021), Pelatihan Character Building untuk Meningkatkan Psychological Well-Being pada Anak Panti Asuhan Puteri Aisyiyah Medan. Jurnal Penelitian Pendidikan, Psikologi dan Kesehatan (J-P3K), 2 (3): 246251. 


\section{PENDAHULUAN}

Masa remaja ialah masa perubahan secara fisik, cara berpikir, kejiwaan, mental, sosial, dan emosional. Masa tersebut ialah era dimana seseorang mulai menelururi identitas serta merupakan era yang rentan terpengaruh oleh pergaulan. Dengan demikian bimbingan dan dampingan orang tua sangat berpengaruh dalam mengontrol dan mengawasi anak remaja. Tidak sedikit anak yang tidak mendapatkan dampingan tersebut akibat beberapa argumen seperti perceraian, kematian, tinggal bersama anggota keluarga lain bahkan di panti asuhan.

Panti asuhan ialah institusi keselamatan kemasyarakatan yang bertanggung jawab menbagikan jasa alternatif pada pemuasan kepentingan fisik, mental, serta sosial pada anak asuhnya, sehingga mendapatkan peluang luas, jelas serta mencukupi bagi pertumbuhan perilaku yang diinginkan. Peranan lembaga panti asuhan hanyalah sebagai pelanjut ayah ibu namun tidak mampu menjadi orang tua seutuhnya. Panti asuhan hanya mencukupi kepentingan fisik serta belum tentu kebutuhan psikis anak asuh. Sehingga tidak sedikit anak asuh menghadapi bermacam persoalan.

Menurut (Ryff, C. D., \& Singer, 2008) psychological well-being ialah suatu bentuk dorongan yang bertujuan memajukan potensi pada diri seseorang secara keutuhan terbagi atas enam elemen yaitu kemampuan pribadi dalam menerima diri sendiri secara apa adanya (self acceptance), meningkatkan lingkungan positif bersama orang lain (positive relationship with other), otonomi (autonomy), menguasai lingkungan (mastery of enviroment), kemampuan menetapkan maksud pada hidup (to set goals in life), serta mampu untuk memajukan serta membangun potensi pribadi (develop personal potential).

Psychological well-being pada anak panti asuhan cenderung rendah, namun dapat ditingkatkan melalui pelatihan character building. Pelatihan character building bertujuan membantu seseorang pada menanamkan ataupun memperbaiki norma yang menjadi karakteristik seseorang sehingga membentuk individu lebih adaptif dan menuju hidup lebih bahagia serta berkualitas. Menurut (Covey, 2013) konsep dalam membentuk karakter memiliki tujuh kebiasaan manusia yang berhasil yaitu proaktif (Proactive), dimulai dengan harapan puncak (begin with the end mind), mendahulukan dulu yang penting (putting the first thing first), berpikir menang/menang (thinkwin/win), mencoba memahami lebih dulu, kemudian meminta dipahami (seek first to understand then to be understood), sinergi (synergy), asahlah gergaji (sharpen thesaw).

Character building disebut juga membentuk perilaku terdiri dari dua silabel yakni to build artinya membangun, memperbaiki serta pembentukan dan character artinya watak, akhlak ataupun budi pekerti yang memperbedakan seseorang dengan lainnya. Jadi, character building ialah usaha untuk mencetak serta menciptakan watak serta perilaku seseorang supaya lebih baik (Megawati, 2004). Character Building juga bisa mendorong dan meningkatkan pencapaian maksud serta peningkatan pembelajaran. Dengan mempunyai 
karakter bagus maka penyimpangan perilaku ataupun watak yang buruk tidak terjadi (Koesoema, 2007).

riset terdahulu yang pernah dilaksanakan oleh Ramadhanie, dkk., (2016) dengan judul Pengaruh Pelatihan Character Building Terhadap Peningkatan Psychological Well-Being Anak Jalanan Binaan Rumah Perlindungan Sosial Anak Yayasan Emas Indonesia Kota Semarang. menerangkan bahwasannya pelatihan character building terbukti berdampak pesat dalam peningkatan psychological well-being pada anak jalanan yang dibina oleh rumah perlindungan sosial anak yayasan emas Indonesia kota Semarang. Hal tersebut menerangkan bahwasannya ada ikatan positif antara pelatihan character building terhadap peningkatan psychological well-being. (Intania et al., 2016)

Manfaat dari studi ini ialah diharapkan bisa menjadi ilmu pengetahuan baru dan landasan untuk periset yang ingin mengkaji mengenai penelitian sejenis dan juga agar bisa membagikan wawasan baru untuk para ilmuwan psikologi. Bagi anak di Panti Asuhan Puteri Aisyiyah Medan diharapkan menyadari tentang pentingnya mempunyai perilaku baik sehingga anak mampu mengubah pola pikir dan perilaku mereka lebih normatif dan memiliki kemampuan untuk lebih mandiri. Para anak asuh diharapkan mampu menjalani hidupnya lebih bahagia dengan keadaan psikis lebih baik serta mampu melakukan fungsi sosialnya secara memadai pada kehidupan masyarakat.

Bagi Panti Asuhan Puteri Aisyiyah Medan selaku pihak penyelenggara diharapkan supaya mampu meninjau
Kembali kebutuhan anak asuh khususnya kebutuhan psikologis karena kebutuhan psikologis bisa menjadi salah satu solusi penanganan anak berbasis Pendidikan karakter.

\section{METODE PENELITIAN}

Observasi percobaan ini dikerjakan melalaui proses seperti berikut:

Hari ke-1: Sebelum diberikan perlakuan lebih dulu dilaksankan pretest dengan memberikan skala psychological well-being kepada peserta pelatihan.

Hari ke-2: Perlakuan berupa pelatihan aspek pertama yaitu jadilah proaktif yang berupa pemberian materi, penayangan video, diskusi dan latihan. Aspek kedua yaitu mengacu pada harapan klimaks berupa pemberian materi, bimbingan serta bermain games dengan puzzle. Serta aspek ketiga yaitu lewati yang penting berupa pemberian materi, diskusi dan latihan.

Hari ke-3: Perlakuan berupa pelatihan aspek keempat yaitu berfikir menang-menang yang berupa pemberian materi, diskusi dan latihan. Aspek kelima yaitu mencoba memahami lebih dulu kemudian dipahami yang berupa pemberian materi, diskusi dan latihan. Kemudian aspek keenam yaitu mewujudkan sinergi yang berupa pemberian materi, diskusi dan bermain games. Kemudian aspek ketujuh yaitu asahlah gergaji yang berupa pemberian materi dan diskusi.

Hari ke-4: Melakukan posttest dengan memberikan skala psychological well-being, ini dilaksanakan untuk melihat apakah pengaruh pemberian pelatihan character building terhadap psychological 
well-being bagi peserta pelatihan lebih baik daripada pretest.

Penghimpunan sampel pada studi ini memakai metode purposive sampling. Subjek pada studi ini ialah Anak Remaja berusia 12-18 tahun yang mendapatkan skor rendah pada hasil tes psychological well-being di Panti Asuhan Puteri Aisyiyah Medan.

studi ini memakai dua variabel yakni variabel bebas serta variabel terikat. Variabel bebas ialah variabel yang dilihat sebagai pemicu timbulnya variabel terikat yang disangka sebagai akibatnya. Variabel bebas pada studi ini ialah pelatihan character building ialah gaya perlakuan yang dikasihkan oleh peneliti. Variabel terikat pada studi ini ialah psychological well-being.

Metode analisis yang dipakai pada studi ini ialah secara kuantitatif serta kualitatif. Analisis kuantitatif menggunakan pengukuran nonparametrik yaitu metode analisis statistic Wilcoxon dengan program bantuan Statistical Product and Service Solution (SPSS) versi 23. Adapun analisa kualitatif bersumber pada data hasil studi serta interview. Uji analisa dipakai untuk melihat pengaruh pelatihan character building terhadap psychological well-being anak Panti Asuhan.

\section{HASIL DAN PEMBAHASAN}

Metode penghimpunan data pada studi ini memakai skala Ryff's Psychological Scale of Well Being (RPSWB) yang dikembangkan Ryff pada tahun 1995 dan sudah dimodifikasi peneliti menjadi 42 aitem. Partisipan berespon dalam derajat kesetujuan atau ketidaksetujuan melalui empat pilihan jawaban, yaitu sangat tidak setuju, tidak setuju, setuju, dan sangat setuju.

Deskripsi data pada studi ini melingkupi skor empirik serta skor hipotetik. Skala psychological well being terdiri dari 21 item dengan poin itemnya bergerak dari empat alternatif jawaban dengan poin satu sampai empat. Rentang maksimum dan minimumnya adalah $21 \times 1$ sampai $21 x 4$, yaitu 21 sampai 84 dengan mean hipotetiknya $(84+21): 2=52,5$. Standar deviasi hipotetik pada studi ini ialah (84-21): $6=10,5$. Dari skala psychological well being yang diisi subjek, maka diperoleh mean empirik sebanyak 54,62 dengan standar deviasi 10,605.

Tabel 1. Perbandingan Data Empirik dan Hipotetik Psychological Well-Being

\begin{tabular}{|c|c|c|c|c|c|c|c|}
\hline \multirow{2}{*}{ Variabel } & \multicolumn{2}{|c|}{ Empirik } & \multirow{2}{*}{ SD } & \multicolumn{3}{|c|}{ Hipotetik } & \multirow[b]{2}{*}{ SD } \\
\hline & Min Max & Mean & & Min & Max & Mean & \\
\hline $\begin{array}{c}\text { Psycholo } \\
\text { gical } \\
\text { Well- } \\
\text { Being }\end{array}$ & $37 \quad 69$ & 54,62 & 10,605 & 21 & 84 & 52,5 & 10,5 \\
\hline
\end{tabular}

Jikalau mean empirik > mean hipotetik sehingga hasil studi didapat akan dikatakan tinggi serta sebaliknya jikalau mean empirik < mean hipotetik sehingga hasil studi dikatakan rendah. Hasil analisis untuk skala Psychological psychological well being diperoleh mean empirik > mean hipotetik yaitu 54,62 > 52,5 maka bisa dijelaskan bahwasannya psychological well being pada subjek riset lebih tinggi daripada populasi biasanya. Selanjutnya subjek terdiri atas tiga klasifikasi. Pengkategorian skor dibagi tiga kategori (Azwar, 2017) dengan rumus yaitu :

$$
\mathrm{X}<(\mu-1 \sigma) \quad \text { tingkat }
$$

Psychological Well-Being rendah $(\mu-1 \sigma) \leq X<(\mu+1 \sigma) \quad$ tingkat Psychological Well-Being sedang 


$$
(\mu+1 \sigma) \leq \mathrm{X}
$$

tingkat

Psychological Well-Being tinggi

Berdasarkan rumus tersebut maka bisa dilihat bahwasannya diperoleh 16 subjek (29\%) memegang psychological well being rendah, terdapat 23 subjek (42\%) memegang psychological well being sedang, serta terdapat 16 subjek (29\%) yang memegang psychological well being tinggi.

Uji asumsi yang dipakai pada studi ini berupa uji normalitas untuk melihat apakah diperoleh penyimpangan data pada cara pengumpulan data. Fungsi uji normalitas ialah untuk melihat apakah distribusi data bernilai normal ataupun tidak. Uji normalitas pada studi ini memakai uji Shapiro-Wilk dikarenakan subjek studi tidak lebih dari 50 orang subjek. Data dinyatakan normal jikalau didapati nilai signifikansi $\mathrm{p}>0.05$. Adapun hasil analisis pada data pretest didapati nilai koefisien $\mathrm{p}$ sejumlah $0.018(\mathrm{p}<0.05)$ dan pada posttest terdapat nilai koefisien p sejumlah $0.829(p>0.05)$. oleh demikian tersebut data posttest dinyatakan terdistribusi normal namun data pretest terdistribusi tidak normal, maka dari itu metode analisis non-parametrik Wilcoxon dibubuhkan untuk meneliti hipotesa pada observasi ini. Berikut tabel uji Normalitas:

Tabel 2. Hasil Uji Normalitas

\begin{tabular}{lcccc}
\hline \multicolumn{2}{c}{ Kelompok } & \multicolumn{3}{c}{ Shapiro-Wilk } \\
& Statistic & Df & Sig. \\
\hline \multirow{2}{*}{ Nilai } & Pretest & .857 & 16 & .018 \\
& Posttest & .969 & 16 & .829 \\
\hline
\end{tabular}

Hipotesis pada studi ini dirumuskan seperti berikut: "Pelatihan character building berpengaruh untuk meningkatkan psychological well-being pada anak Panti Asuhan Puteri Aisyiyah Medan"
Hasil uji statistik yang selesai dikerjakan memakai uji Wilcoxon didapati nilai $\mathrm{p}$ value sejumlah 0.000 . Secara statistik, jikalau nilai $\mathrm{p}<0.05$ sehingga hipotesa diterima. Oleh sebab itu, menurut hasil analisis tersebut bisa ditarik kesimpulan bahwasannya pelatihan character building berpengaruh untuk meningkatkan psychological well-being pada anak Panti Asuhan Puteri Aisyiyah Medan. Berikut tabel uji hipotesa menggunakan Wilcoxon :

\begin{tabular}{lr}
\hline Tabel 3. Hasil Uji Wilcoxon & Posttest - Prettest \\
\hline Z & $-3.521^{\mathrm{b}}$ \\
Asymp. Sig. $\quad$ (2-tailed) & .000
\end{tabular}

Hasil dari studi pada 16 orang anak Panti Asuhan Puteri Aisyiyah Medan yang menjadi subjek observasi membuktikkan bahwa pelatihan character building berpengaruh untuk meningkatkan psychological wel-being anak Panti Asuhan Puteri Aisyiyah Medan, dimana teruji efektif dalam hasil uji Wilcoxon dengan perolehan nilai $\mathrm{p}$ value sejumlah 0.000 . Secara statistika, jikalau nilai $\mathrm{p}<0.05$ sehingga hipotesa diterima.

\section{SIMPULAN}

Dari hasil studi yang selesai dilaksanakan oleh periset sehingga bisa disimpulkan bahwasannya pelatihan character building efektif dalam meningkatkan psychologycal well being pada anak di Panti Asuhan Puteri Aisyiyah Medan. Hal tersebut ditunjukkan dari hasil uji statistik yang pernah dikerjakan memakai uji Wilcoxon didapati nilai $\mathrm{p}$ value sejumlah 0.000 . Secara statistik, jikalau nilai $\mathrm{p}<0.05$ sehingga hipotesa 
diterima. Dengan demikian, kita bisa mengambil kesimpulan dari analisis tersebut bahwasannya pelatihan character building berpengaruh untuk meningkatkan PWB pada anak di Panti Asuhan Puteri Aisyiyah Medan.

\section{DAFTAR PUSTAKA}

Azwar, S. (2017). METODE PENELITIAN PSIKOLOGI (1st ed.). Pustaka Pelajar.

Covey, S. . (2013). 7 kebiasaan manusia yang sangat efektif. Bina Rupa Aksara.

Fitri, B. A., \& Amna, Z. (2016). PSYCHOLOGICAL WELL-BEING PADA REMAJA PANTI ASUHAN DI KOTA BANDA ACEH. International Journal of Child and Gender Studie, 2(1), 119-128. https://doi.org/10.22373

Dr. Ramesh D. Waghmare. (2016). A Study of Psychological Well Being Among Male and Female College Students. International Journal of Indian Psychology, 3(3), 27-31. https://doi.org/10.25215/0303.118

Franzen, J., Jermann, F., Ghisletta, P., Rudaz, S., Bondolfi, G., \& Tran, N. T. (2021). Psychological Distress and Well-Being among Students of Health Disciplines: The Importance of Academic Satisfaction. International Journal of Environmental Research and Public Health, 18(4), 2151. https://doi.org/10.3390/ijerph18042151

Hailegiorgis, M. T., Berheto, T. M., Sibamo, E. L., Asseffa, N. A., Tesfa, G., \& Birhanu, F. (2018). Psychological wellbeing of children at public primary schools in Jimma town: An orphan and non-orphan comparative study. PLOS ONE, 13(4), e0195377. https://doi.org/10.1371/journal.pone.01953 77

Halim, C. F., \& Dariyo, A. (2017). Hubungan Psychological Well-Being dengan Loneliness pada Mahasiswa yang Merantau. Journal Psikogenesis, $\quad 4(2), \quad 170$. https://doi.org/10.24854/jps.v4i2.344

Hartato, I., Basaria, D., \& Patmodewo, S. (2018). TERAPI WELL-BEING UNTUK MENINGKATKAN PSYCHOLOGICAL WELLBEING PADA REMAJA YANG TINGGAL DI PANTI SOSIAL BINA REMAJA X. Psibernetika, 10(1), 20-29. https://doi.org/10.30813/psibernetika.v10i1 .1038

Ifdil, I., Sari, I. P., \& Putri, V. N. (2020). Psychological well-being remaja dari keluarga broken home. SCHOULID: Indonesian Journal of School Counseling, $\quad 5(1)$, https://doi.org/10.23916/08591011

Intania, S. R., Nugraha Arif, K., \& Astriana. (2016). Pengaruh Pelatihan Character Building Terhadap Peningkatan Psychological WellBeing Anak Jalanan Binaan Rumah Perlindungan Sosial Anak Yayasan Emas Indonesia Kota Semarang TO IMPROVE LEVEL OF PSYCHOLOGICAL WELL-BEING. EJournal Psikologi, 4(1), 1-9.

Makvana, M. B. (2020). Psychological well-being of people. The International Journal of Indian Psychology, $\quad 8(1), \quad 1-4$. https://doi.org/10.25215/0801.052

Nugraha, M. A., \& Agus, B. (2019). Hubungan Gratitude Dengan Psychological Well Being pada Remaja di Panti Sosial Asuhan Anak Al Fien Bandung. Prosiding Psikologi, 5(2), 604611.

Prabowo, A. (2017). GRATITUDE DAN PSYCHOLOGICAL WELLBEING PADA REMAJA. Jurnal Ilmiah Psikologi Terapan, 5(2), 260. https://doi.org/10.22219/jipt.v5i2.4857

Ryff, C. D., \& Singer, B. H. (2008). Know thyself and become what you are: A eudaimonic approach to psychological well-being. Journal of Happiness Studies: An Interdisciplinary Forum on Subjective Well-Being, 19-39. https://doi.org/10.1007/s10902-006-9019-0

Srisailamaiah. M, Suresh. K, \& Srikanth Reddy. V. (2016). Depression and Psychological WellBeing among Living Institutionalized and Non- Institutionalized Elderly. International Journal of Indian Psychology, 3(4). https://doi.org/10.25215/0304.034

Wulansari, O. D., \& Setiawan, J. L. (2019). Hubungan antara Psychological Well-being dan Marital Adjustment pada Remaja. Psychopreneur Journal, 3(1), 36-46. 